\title{
Internet of Things: Smart Device for Smart City
}

\author{
Deepak Bhatt \\ Department of Computer Science and Engineering \\ UTU Dehradun Uttarakhand India
}

\author{
Sanjay Kumar \\ Department of Computer Science and Engineering \\ UTU Dehradun Uttarakhand India
}

\begin{abstract}
In this era of technology, it is very difficult to imagine the world without assistant of smart devices. Our dependency on computer machine has led to the rapid development of smart devices that can make our life more easier and comfortable. More and more things can connect to the internet these days and these come in the form of objects that we use on a daily basis. Some researcher predict that in year 2020 around 100 million devices will be connected through internet, so this is the time to make such devices which can ease the life of public and help to make smart people, smart home, smart environment and a smart city. This paper presents the application of smart device using the Onion Omega 2 development board and smart phone. The proposed device helps to find households objects and saves our time in order to find those objects by ourselves.
\end{abstract}

\section{Keywords}

Internet of Things, Onion Omega 2, Smart Phone

\section{INTRODUCTION}

The internet of things, or IoT refers to all those physical devices that are connected to the internet, collecting and sharing data. The internet of things integrates the people, physical devices and different kind of technologies with sensors, development devices which is connectable and is used to enable distant monitoring [1,5]. In recent past, Iot was most interesting to business and manufacturing, where its application is sometimes known as machine-to-machine. But now the idea of Iot is applying everywhere and in every field. The main motive of internet of thing is to connect and enable everyday object like television, coffee machine, refrigerator, fan, medical equipment, home security etc with the internet. There are lots of software and hardware available which can be used to fulfill the demand. There are various kind of sensor devices and chip level technology which is used to design intelligent and smart devices. The major significant trend in the field of IoT in recent years is the explosive growth of devices connected and controlled by the internet. With the fast growing technology, there is need to make a smart devices which helps to reduce human effort. As people generally keep their daily basis objects somewhere and forget. So in that situation it sometimes becomes very difficult to search for those lost objects and sometimes it takes most of our valuable time to search for those missing objects. Now its possible to turn anything into the part of Iot. Lets imagine a situation that "you have kept your car keys somewhere at home and forget the exact location of keys". What if "without any effort you got your keys"? In order to reduce human effort and saves their precious time we have come up with the idea of designing such a device that can make human life more comfortable and easy. This paper aim is to use open source platform and make a device which can be used for home or office purpose. This device is used to find the small things like keys, tv or ac remotes and other small things. This device is mainly the contribution and effort for giving the wings to the idea of smart city. Remaining paper is summarized as follows: Section II, includes the summary of related work. Section III describes the proposed model. Section IV explores experiment setup and results. Conclusion and future work are stated in Section V.

\section{MOTIVATION}

Recent development in the field of digital technologies makes the cities much smarter. A small city equipped with smart devices makes the city more secure and make human life more easier. When there is a discussion of smart city then it refers a complete smart life in a smart city. For smart city there is need a heterogeneous environment, which includes different objects, shared things and security things. Some of the main aspects of a smart city as shown in Fig. 1

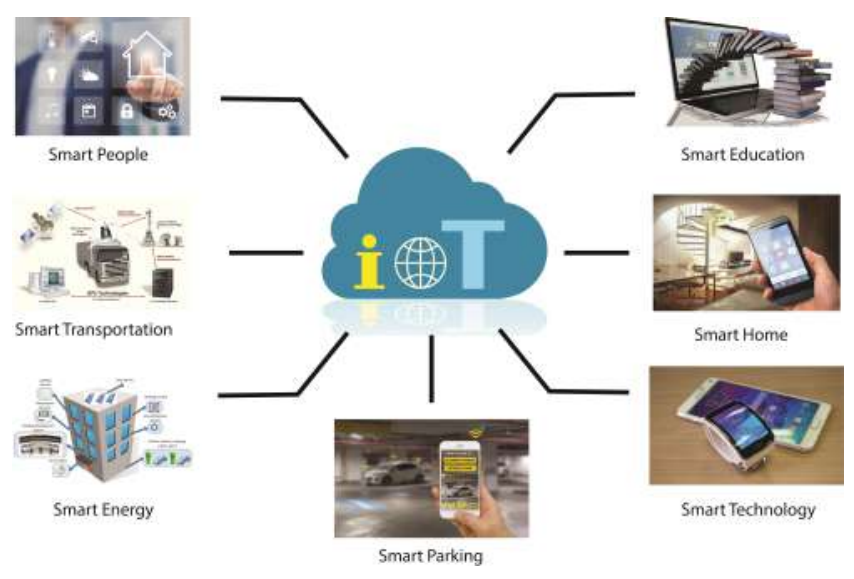

Fig. 1: Some Aspects of Smart City

\section{RELATED WORK}

The existing works in the field of Internet of Thing are as follows:

1. Car security using IoT

2. Power extension cord security using IoT

3. Healthcare 


\subsection{Car Security using IoT[1]}

This paper presents a car security system by using Arduino Uno R3 development board, a sensor shield and a smartphone. The proposed device is used for car security which gives access of car through internet and GPS, to the car owner in case of any kind of threat. The best utility of this work is to access security system at any distance using IoT protocols. The main key features of this proposed security system is as follows: 1) Automatic notification via text message in case of car stolen or in case of speed of car reaches a certain threshold limit. 2) Enable skype call to see the activities inside the car. 3) Allow user to turn On the Gps tracker by sending an appropriate message to the samrtphone. 4) It also provide facility to stop and restart the car at any point of time by sending the messages like stop the car and restart the car. 5) It also provide facility like locking and shut down of door and windows by a means of sending message to the smartphone.

\subsection{Power extension cord security by IoT[2]}

This paper focuses on the applications of internet of things and provide an intelligent security- the intelligent extension cord using the concept of maker in IoT. In electrical equipment there is always a risk of heating inside the electronic device due to high electric current and some other failure in it which makes damage and other hazards. For the solution of this problem the study targets a smart, intelligent security by the use of internet of things. The presence of voltage is one of the common factor in many of the electrical incidents that results in injuries or death. So, in order to deal with these situations they have design an intelligent power extension cord with the following objective: 1) To examine the material and function of the extension cord. 2) To determine the benefits of temperature monitoring applications. 3) To enhance the safety of electricity. In this design, the extension board is connected via internet. Using mobile phone user can on and off the extension board. In case of any harm in extension board due to overheating or any short circuit, the extension board will sends a notification to the user smart phone and then user can access the device and have authority to switch off the device.

\subsection{Healthcare [4]}

The Internet of Things develops smart objects and devices which are used in the field of healthcare worldwide. In last few years, the medical and health care becomes one of the attractive and challenging application of IoT. It is a smart way to ensure the health of the citizens. The IoT has a potential to provide medical application such as remote healthcare monitoring like Glucose level monitoring, ECG monitoring, Blood pressure monitoring, Body temperature monitoring, Oxygen saturation monitoring, fitness training and chronic diseases. IoT based health services are expected to be cost effective, increase quality of life and helps to enrich users experience. These technology are using now days and there is a lot.

\section{STRUCTURE AND FUNCTION}

System designed including two parts: Smart phone App and Smart Device. The smart device which is connected through mobile phone APP via Wi-Fi can be placed into any small important things like key, remote, iron, wallet and other household small things. Generally at home or in office we use some common things( like key, wallet, TV remote, Ac remote) and placed it somewhere and forget where we placed it. Then to search for those things becomes very irritating and time consuming. Using this smart device we can find these things and saves our time and effort. In this smart world, there is need of smart devices which is used in the society to reduce the human effort and ease the life of human being. Function chart in Fig. 2. shows that how different smart devices can be connected through home or office Wi-Fi system.

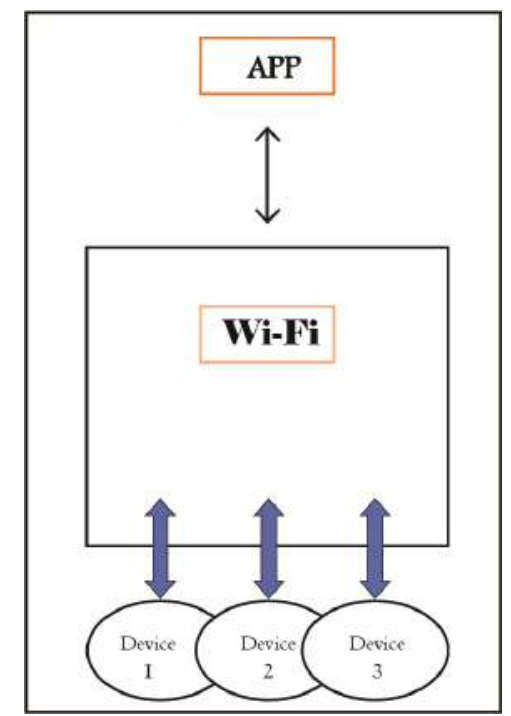

Fig. 2: Function chart of smart device system

\subsection{Smart Phone APP}

In the recent few years, smart phone becomes the necessary prerequirement of the people. Smart phones are used in many platforms like in education, banking, transportation, health [6][8]. In this paper, an App is designed which is used to link with the smart device. Using this app user can check the location of object, it is not like GPS device but a smart device which is used to find household things through IoT concept. The interface design of the app is simple and user can easily access the app, it is same as other application and provides the right thing in right place [9].

\subsection{Smart Device}

The device is compact in size and hence can be easily fit or put into any household things like key, remote, some important files, wallet, keys etc. for instance, if user is unable to find the thing then user can use smart phone and use the smart app. Then user just need to click in the app button which will automatically connect with the server then server will connect with the device through Wi-Fi enable smart device and then the device sounds, so user can easily judge and notice the sound. This way user can easily find the lost and missing objects at home or office without making much effort and time.

\section{DESIGN: COMPONENTS AND MATERIAL}

The setup required an Omega2 board because of its compact size and it is easy to fit onto any other device or objects and easy to carry, this board is Wi-Fi enabled which is already inbuilt in it, a buzzer which is used with it and need lithium $3.0 \mathrm{v}-3.7 \mathrm{v}$ batteries as show in fig. 5 . 


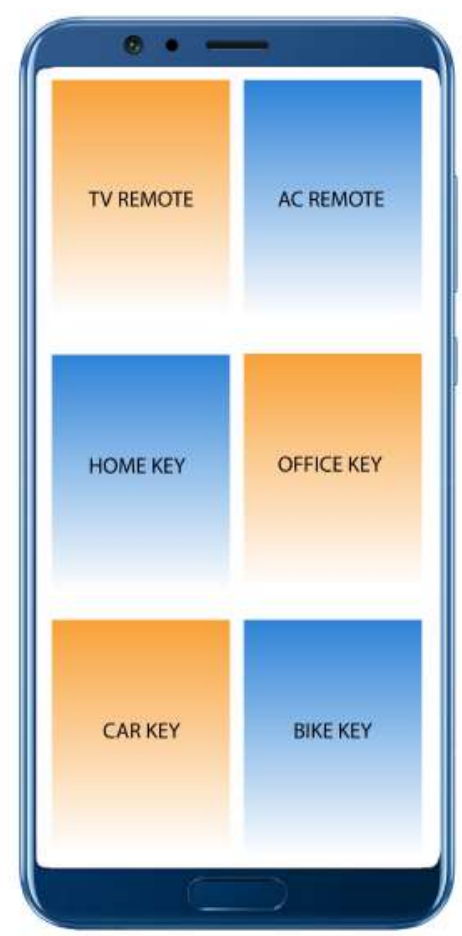

Fig. 3: Interface with intelligent devices App

Table 1. : Device Specifications

\begin{tabular}{|l|c|}
\hline Operating Systems & OpenWrt \\
\hline System on chip used & MediaTekMT7688 \\
\hline CPU & $\begin{array}{c}580 \text { MHZ 32-bit } \\
\text { computing Single core MIOS 24KEC }\end{array}$ \\
\hline Memory & $64 \mathrm{MB}$ \\
\hline Storage & $16 \mathrm{MB}$ \\
\hline Power & 0.6 watts \\
\hline
\end{tabular}

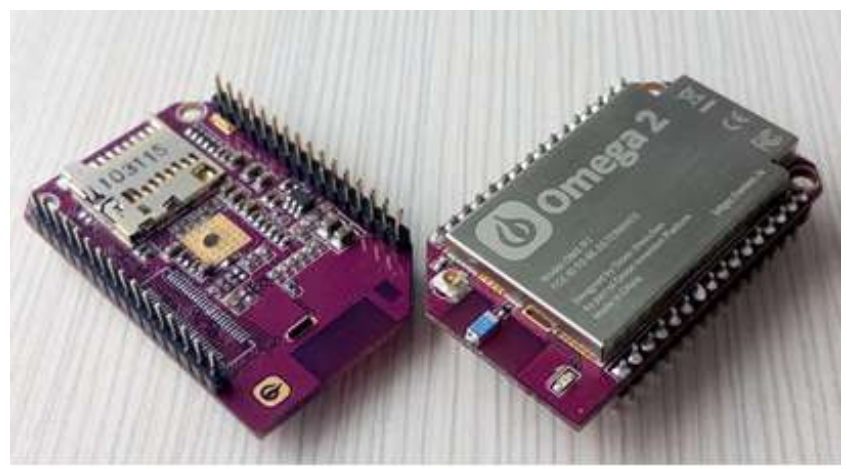

Fig. 4: Onion Omega2 Board

\section{WORKING PRINCIPLE}

The open source development is a reliable means of designing and developing projects in this modern era. In this paper, we have used

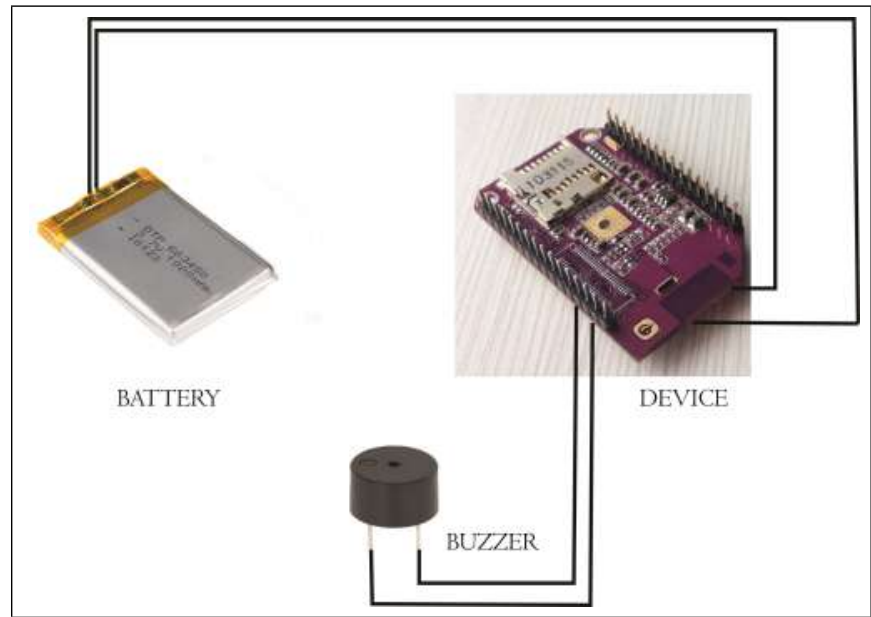

Fig. 5: Smart Device Board Module

an Omega2 board having inbuilt Wi-Fi system through which the board can connect through internet and one buzzer with power supply using lithium battery and a smartphone to implement the idea. The idea focuses on the need to design a system, which is quite interesting and have very important role in day to day life. The overall working of the proposed work can be seen in fig. 6 . Though we can find anything lost arround us as well as we can access those lost item remotely. The best possible utility of this proposed work is that we can access the smart device from any distance or place . For instance, if we have lost our tv remote somewhere at home. In this case, First we need to use the smart app which must be already installed at our android phone. Using this smart app we can search for those lost item. As all the smart device data is stored in the server. Then server will help to access for those lost item. The server access for smart device using internet. As the smart device have an inbuilt wifi connectivity and have a buzzor inside it. So when the device get detected, we can hear a beep sound. Hence In this way, we can find our lost thing.

\section{DEVICE TESTING}

In this testing we use battery for power supply with $6 \mathrm{v}$, Voltage regulator Ams 1117 which can converts $6 \mathrm{v}$ to $3 \mathrm{v}$ or according to the device and a Buzzer. This testing is successfully done as shown in fig 7 .

\section{CONCLUSION}

With the aim of transforming real-world objects into smart objects and connects them through the internet, we have design a smart device and presents its function, architecture and material. The proposed device is tested and implemented successfully. This smart device provides an intelligent security to the households things and is completely monitored through the mobile application. Many times we keep our personnel things somewhere and forget. It helps us to find out household objects and saves our time in order to find those objects by ourselves. This work is simply a contribution to give a hope for making smart city with smart devices.

\section{REFERENCES}

[1] Sehgal, V. K., Mehrotra, S., \& Marwah, H. (2016, July). Car security using Internet of Things. In Power Electronics, Intel- 


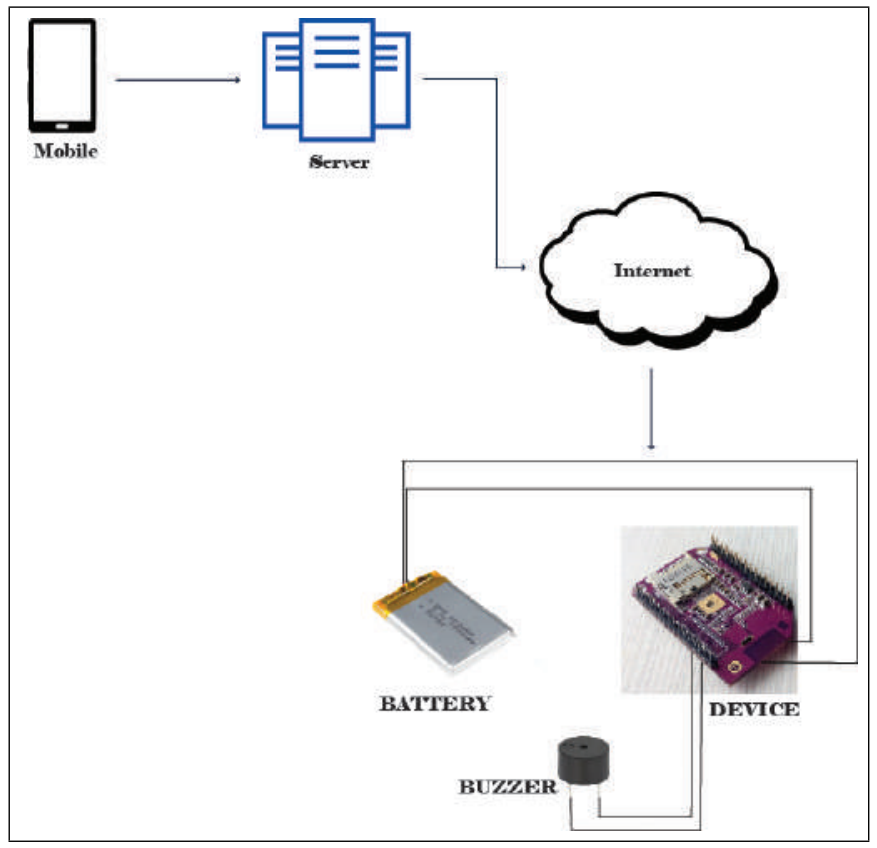

Fig. 6: The Architecture of Smart Device

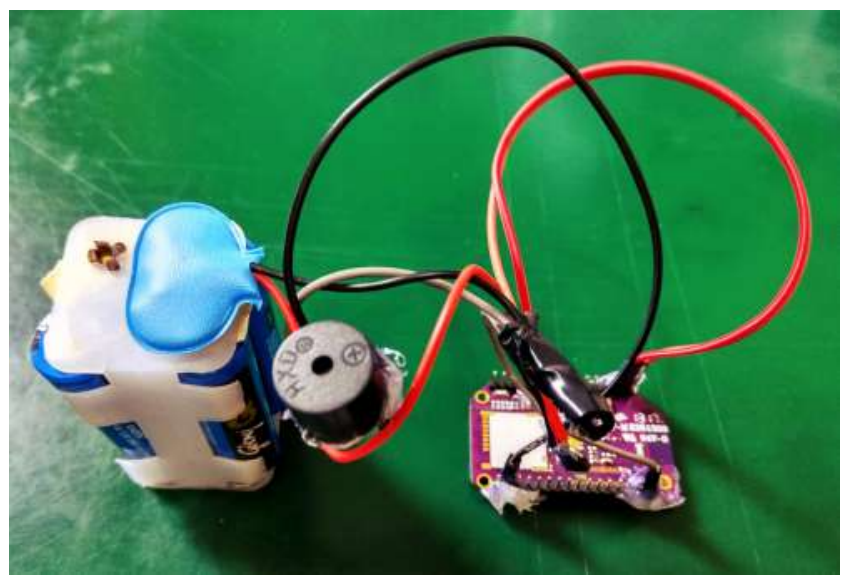

Fig. 7: Overall Omega2 Board Testing

ligent Control and Energy Systems (ICPEICES), IEEE International Conference on (pp. 1-5). IEEE.

[2] Cheng, K. M., Tseng, C. E., \& Tseng, C. H. (2017, May). Maker and Internet of Things application in the intelligent security by example of power extension cord. In Applied System Innovation (ICASI), 2017 International Conference on (pp. 239-241). IEEE.

[3] Dalvi, S. A., \& Shaikh, M. Z. (2017). Internet of Things for Smart Cities. Imperial Journal of Interdisciplinary Research, 3(7).

[4] Islam, S. R., Kwak, D., Kabir, M. H., Hossain, M., \& Kwak, K. S. (2015). The internet of things for health care: a comprehensive survey. IEEE Access, 3, 678-708.

[5] Saha, H. N., Mandal, A., \& Sinha, A. (2017, January). Recent trends in the Internet of Things. In Computing and Commu- nication Workshop and Conference (CCWC), 2017 IEEE 7th Annual (pp. 1-4). IEEE.

[6] Jia, J., \& Chen, Z. (2015, October). The Effect of Smart Phones Application in Regular University English Class on Students Learning Performance. In Educational Innovation through Technology (EITT), 2015 International Conference of (pp. 131-136). IEEE.

[7] Abuzalata, M., Momani, M., Fayyad, S., \& Abu-Ein, S. (2012). A Practical Design of Anti-Theft Car Protection System Based on Microcontroller. American Journal of Applied Sciences, 9(5), 709.

[8] Sutar, S. H., Koul, R., \& Suryavanshi, R. (2016, January). Integration of Smart Phone and IOT for development of smart public transportation system. In Internet of Things and Applications (IOTA), International Conference on (pp. 73-78). IEEE.

[9] Lu, J., Chen, Q., \& Chen, X. (2012, July). App interface study on how to improve user experience. In Computer Science \& Education (ICCSE), 2012 7th International Conference on (pp. 726-729). IEEE.

[10] Saha, H. N., Mandal, A., \& Sinha, A. (2017, January). Recent trends in the Internet of Things. In Computing and Communication Workshop and Conference (CCWC), 2017 IEEE 7th Annual (pp. 1-4). IEEE.

[11] Hsieh, C. T. (2016, October). Development of an integrated system of 3D printer and laser carving. In Microsystems, Packaging, Assembly and Circuits Technology Conference (IMPACT), 2016 11th International (pp. 420-423). IEEE.

[12] Schaumont, P. (2017, March). Security in the Internet of Things: A challenge of scale. In 2017 Design, Automation \& Test in Europe Conference \& Exhibition (DATE) (pp. 674679). IEEE.

[13] Pal, D., Funilkul, S., Charoenkitkarn, N., \& Kanthamanon, P. (2018). Internet-of-Things and Smart Homes for Elderly Healthcare: An End User Perspective. IEEE Access, 6, 10483-10496.

[14] Analytics, I. (2014). Why the internet of things is called internet of things: Definition, history, disambiguation.

[15] Łatala, P., Gapar, V., \& Butka, P. (2018, February). Using IoT devices for movement detection in medical environmentProof of concept. In Applied Machine Intelligence and Informatics (SAMI), 2018 IEEE 16th World Symposium on (pp. 000061000066). IEEE.

[16] Jang, I., Lee, D., Choi, J., \& Son, Y. S. (2018, January). Knowledge of Things: A novel approach to share self-taught knowledge between IoT devices. In Consumer Electronics (ICCE), 2018 IEEE International Conference on (pp. 1-2). IEEE

[17] Tanwar, S., Patel, P., Patel, K., Tyagi, S., Kumar, N., \& Obaidat, M. S. (2017, July). An advanced Internet of Thing based security alert system for smart home. In Computer, Information and Telecommunication Systems (CITS), 2017 International Conference on (pp. 25-29). IEEE. 